Submitted to: Journal of Power Sources

Date: March 2, 2017

\title{
Electrical power production from low-grade waste heat using a thermally regenerative ethylenediamine battery
}

\author{
Mohammad Rahimi ${ }^{1}$, Adriana D'Angelo ${ }^{2}$, Christopher A. Gorski ${ }^{3}$, Onofrio Scialdone ${ }^{2}$, Bruce E. \\ $\operatorname{Logan}^{3, *}$ \\ ${ }^{1}$ Department of Chemical Engineering, The Pennsylvania State University, University Park, Pennsylvania 16802, \\ USA \\ ${ }^{2}$ Dipartimento dell'Innovazione Industriale e Digitale, Ingegneria Chimica, Gestionale, Informatica, Meccanica, \\ Università degli Studi di Palermo, Viale delle Scienze, 90128 Palermo, Italy \\ ${ }^{3}$ Department of Civil and Environmental Engineering, The Pennsylvania State University, University Park, \\ Pennsylvania 16802, USA \\ *Corresponding Author. Telephone: +1 814863 7908. Fax: +1 814863 7304. E-mail: blogan@ psu.edu.
}

\begin{abstract}
Thermally regenerative ammonia-based batteries (TRABs) have been developed to harvest lowgrade waste heat as electricity. To improve the power production and anodic coulombic efficiency, the use of ethylenediamine as an alternative ligand to ammonia was explored here. The power density of the developed ethylenediamine-based battery (TRENB) was $85 \pm 3 \mathrm{~W} \mathrm{~m}^{-2}$ electrode area with $2 \mathrm{M}$ ethylenediamine, and $119 \pm 4 \mathrm{~W} \mathrm{~m}^{-2}$ with $3 \mathrm{M}$ ethylenediamine. This power density was $68 \%$ higher than that of TRAB. The energy density was $478 \mathrm{Wh} \mathrm{m}^{-3}$-anolyte, which was $\sim 50 \%$ higher than that produced by TRAB. The anodic coulombic efficiency of TRENB was $77 \pm 2 \%$, which was more than twice that obtained using ammonia in TRAB (35\%). The higher anodic efficiency reduced the difference between the anode dissolution and cathode deposition rates, resulting in a process more suitable for closed loop operations. The thermalelectric efficiency, based on ethylenediamine separation using waste heat was estimated to be $0.52 \%$, which was lower than that of TRAB $(0.86 \%)$, mainly due to the more complex separation process. However, this energy recovery could likely be improved through optimization of ethylenediamine separation process.
\end{abstract}


Keywords: low-grade waste heat; thermally regenerative battery; ethylenediamine; high power production; thermoelectrochemical systems

\section{Introduction}

A vast amount of low-grade, thermal energy (temperature $<130{ }^{\circ} \mathrm{C}$ ) is available globally at industrial plants and from solar and geothermal sources [1-3]. Converting this low-grade heat into electrical power has drawn increasing attention due to its wide availability and energy potential [4-8]. Different types of thermoelectrochemical systems (TESs) are being investigated to convert low-grade waste heat to electrical power [9-12]. Most of the reported TESs rely on using a chemical that has temperature-dependent reduction and/or oxidation potentials in aqueous solutions, but the performance of these TESs need to be improved in terms of electrical power densities and thermal-electric conversion efficiencies [11, 13]. For example, a maximum power density of $1.5 \mathrm{~W} \mathrm{~m}^{-2}$-electrode area with a Carnot efficiency of $1.4 \%$ was achieved in a TES operated with a ferrocyanide/ferricyanide redox solution and carbon nanotube electrodes when operated with a temperature difference of $60^{\circ} \mathrm{C}$ [14]. The power density was increased to $6.6 \mathrm{~W} \mathrm{~m}^{-2}$-electrode area (Carnot efficiency of 3.95\%) using carbon nanotube aerogel sheets with a $51{ }^{\circ} \mathrm{C}$ temperature difference, but this required the use of platinum [15]. Even though this system could be viable due to the relatively high Carnot efficiencies [16], the systems still has a relatively low power density and it required the use of a precious metal.

An alternative approach to convert waste heat to electricity, called a thermally regenerative battery (TRB) based on using ammonia (TRAB), was recently shown to be capable of producing a significantly higher power density of $\sim 80 \mathrm{~W} \mathrm{~m}^{-2}$-electrode area, with a Carnot thermal-electric conversion efficiency $(6.2 \%)$ that was greater than previous systems [17]. Unlike TESs which 
rely on reversible redox couples, TRBs operate using chemical potentials obtained by adding ligands into a metal salt solution [17-19]. In a TRAB, copper ammine complexes are produced when ammonia is used as the ligand in the anolyte, but not in the catholyte. Copper reduction occurs at the cathode while copper oxidation proceeds on the anode immersed in the ammonia ligand solution, according to:

$$
\begin{array}{ll}
\mathrm{Cu}^{2+}{ }_{(\mathrm{aq})}+2 \mathrm{e}^{-} \rightarrow \mathrm{Cu}_{(\mathrm{s})} & E^{0}=+0.34 \mathrm{~V} \\
\mathrm{Cu}_{(\mathrm{s})}+4 \mathrm{NH}_{3(\mathrm{aq})} \rightarrow \mathrm{Cu}\left(\mathrm{NH}_{3}\right)_{4}{ }^{2+}{ }_{(\mathrm{aq})}+2 \mathrm{e}^{-} & E^{0}=-0.04 \mathrm{~V}
\end{array}
$$

where $E^{0}$ is the standard reduction potential (vs. a standard hydrogen electrode, SHE) [20]. After discharging the electrical power, the ammonia is separated from the anolyte using conventional technologies such as distillation and low-grade waste heat. The extracted ammonia is then added to the other chamber so that the former anode electrode functions as the cathode for the next discharge cycle (Fig. S1). This alternating cycle of electrode dissolution/deposition allows the $\mathrm{Cu}$ electrodes to be operated in closed-loop cycles as long as the mass lost and gained on the electrodes is balanced in each cycle. While the cathodic deposition of copper is efficiently regained from the current (i.e., the increase in mass of the electrode is equal to the expected value based on the number of electrons transferred), the conversion of anode copper into current of TRABs is only $35 \%$ (i.e., approximately three times as much copper dissolves from the electrode as would be predicted based on the numbers of electrons transferred) [17-19]. This low conversion of anode copper into current (i.e., anodic columbic efficiency, ACE) of TRAB would limit its use in closed-loop cycles as there would be a net loss of anode copper into solution for each cycle, eventually requiring the electrodes to be replaced.

The use of ethylenediamine as an alternative ligand to ammonia was explored here as a method to increase the power production as well as improve ACE. In theory, the anode open 
circuit potential of a TRB can be improved by using a ligand in which the complexation reaction $\left(\mathrm{Cu}+\mathrm{n} \mathrm{L} \rightarrow\left[\mathrm{Cu}(\mathrm{L})_{\mathrm{n}}\right]^{2+}+2 \mathrm{e}^{-} ; \mathrm{L}\right.$ : ligand) has a higher standard reduction potential than the copper ammonia complex (Eqn. $2 ;-0.04 \mathrm{~V}$ ). For the complexation reaction of copper and ethylenediamine (en), the anode standard reduction potential is $-0.12 \mathrm{~V}$, as [21]:

$$
\mathrm{Cu}_{(\mathrm{s})}+2 \mathrm{en}_{(\mathrm{l})} \rightarrow \mathrm{Cu}(\mathrm{en})_{2}{ }^{2+}{ }_{(\mathrm{aq})}+2 \mathrm{e}^{-} \quad E^{0}=-0.12 \mathrm{~V}
$$

The performance of a thermally regenerative ethylenediamine-based battery (TRENB) was examined in terms of power and energy densities, and electrode coulombic efficiencies, and compared to that of the previously developed ammonia-based system using copper electrodes and copper nitrate electrolytes.

\section{Materials and Methods}

\subsection{TRB construction and operation}

The cells used for all tests were constructed as previously described for TRABs [17, 22]. The cells consisted of a cathode and an anode chamber, each $4 \mathrm{~cm}$ long and $3 \mathrm{~cm}$ in diameter, separated by an anion exchange membrane (AEM; Selemion AMV, Asashi Glass, Japan) with a projected surface area of $7 \mathrm{~cm}^{2}$. Two $0.8 \pm 0.05 \mathrm{~cm} \times 2 \pm 0.05 \mathrm{~cm}$ pieces of copper mesh $(50 \times 50$ mesh; McMaster-Carr, OH) connected by copper wire were used as the electrodes, with each electrode placed $1 \mathrm{~cm}$ from the membrane (Fig. S2). To monitor the electrode potentials, two $\mathrm{Ag} / \mathrm{AgCl}$ reference electrodes $(+0.211 \mathrm{~V}$ vs. SHE; RE-5B; $\mathrm{BASi})$ were inserted $1 \mathrm{~cm}$ away from each electrode ( $2 \mathrm{~cm}$ away from the membrane). To facilitate the mass transfer of ions to the electrode, the catholyte was mixed using a magnetic stirrer $(6.4 \times 15.9 \mathrm{~mm}$; VWR $)$ at $600 \mathrm{rpm}$ [17]. 
The electrolytes were prepared by dissolving $0.1 \mathrm{M}$ of $\mathrm{Cu}\left(\mathrm{NO}_{3}\right)_{2}$ (Sigma-Aldrich) in deionized water with $5 \mathrm{M} \mathrm{NH}_{4} \mathrm{NO}_{3}$ as the supporting electrolyte to increase conductivity. Either ammonium hydroxide (for TRAB; $2 \mathrm{M}$ final concentration; $5 \mathrm{~N}$ solution, Sigma-Aldrich) or ethylenediamine (for TRENB; ReagentPlus ${ }^{\circledR}, \geq 99 \%$, Sigma-Aldrich) was added only to the anolyte to form the copper complex and create the potential difference between the cathode and anode chambers.

\subsection{TRB performance evaluation}

Polarization tests were performed using a potentiostat (model 1470E, Solatron Analytical, Hampshire, England) to measure the cell voltage $(U)$, and each electrode potential, at room temperature $\left(\sim 23{ }^{\circ} \mathrm{C}\right)$. External resistances were switched every 4 min from open circuit to a minimum of $1.4 \Omega$. Both current density $\left(i=U / R A, \mathrm{~A} \mathrm{~m}^{-2} ; i\right.$ : current density, $U$ : voltage, $R$ : external resistance, $A$ : surface area), and power density $\left(P=U^{2} / R A, \mathrm{~W} \mathrm{~m}^{-2}\right)$ were normalized to a single electrode projected surface area $\left(1.6 \mathrm{~cm}^{2}\right)$ [23]. The total charge transferred over the entire cycle was calculated by integrating the current-time profile $Q=\int I d t_{s}$, where $Q$ is the total charge (C), $I$ the current (A), and $t_{s}$ time (s). The energy density, normalized to the total electrolyte volume $\left(E, \mathrm{Wh} \mathrm{m}^{-3}\right)$, was calculated as $E=\int U I d t_{h} / V$, where $U$ is the voltage (V), $I$ the current (A), $t_{h}$ the cycle time (h), and $V$ the total volume $(2 \times 28 \mathrm{~mL})$.

The discharging energy efficiency $\left(\eta_{d}\right)$ was calculated as the ratio between actual energy density produced in the experiments and the theoretical energy density stored in the solutions. The theoretical energy density was calculated using the equation $\Delta G=n F E$, where $F$ is Faraday's constant $\left(96485 \mathrm{C} \mathrm{mol}^{-1}\right.$ ) and $E$ the measured open-circuit voltage (V). The $\Delta G$ calculated for TRENB was $110 \mathrm{~kJ} \mathrm{~mol}^{-1}$, while that of TRAB with the same concentration of ligand (2 M) was $89 \mathrm{~kJ} \mathrm{~mol}^{-1}$. The $\Delta G$ of TRENB further enhanced by increasing the ligand concentration to 116 
$\mathrm{kJ} \mathrm{mol}^{-1}(3 \mathrm{M})$ and $124 \mathrm{~kJ} \mathrm{~mol}^{-1}(4.5 \mathrm{M})$. Thermal energy efficiency $\left(\eta_{\mathrm{t}}\right)$ was calculated as the ratio between the actual energy density produced and the required thermal energy for anolyte regeneration estimated using Aspen HYSYS (Cambridge, MA) [17, 18].

Electrochemical impedance spectroscopy (EIS; VMP3, Bio-Logic) was performed to identify components of the impedance. All EIS tests were measured over a frequency range of $100 \mathrm{kHz}$ to $0.1 \mathrm{~Hz}$ with a sinusoidal amplitude of $10 \mathrm{mV}$. Both TRAB and TRENB were discharged at 0.2 $\mathrm{V}$ for 5 min with a stable current production before the addition of sinusoidal perturbation to achieve a pseudo steady state. The EIS spectra were fitted into a simplified Randles equivalent circuit to identify the compartments of impedance (Fig. S3).

Cyclic voltammetry $(\mathrm{CV})$ was used to identify the reactions in the anode chamber. $\mathrm{CV}$ studies of the anode electrode of both TRAB and TRENB were performed using a potentiostat (VMP3, BioLogic) and a glassy carbon as the working electrode, a reactor with a platinum wire as the counter electrode, and an $\mathrm{Ag} / \mathrm{AgCl}$ reference electrode. $\mathrm{CVs}$ were run at the potential range of $-0.6 \mathrm{~V}$ to $0.6 \mathrm{~V}$ with different scan rates $\left(10,25,100 \mathrm{mV} \mathrm{s}^{-1}\right)$ and potential ranges.

The cathodic coulombic efficiency $(C C E)$ was calculated as the ratio between actual produced charge and the theoretical amount of charge based on the mass change of the electrode to find the dominant electrochemical reaction in the catholyte, as:

$$
\operatorname{CCE}(\%)=\frac{\left(m_{f, c}-m_{0, c}\right)}{\frac{Q M}{2 F}} \times 100
$$

where $m_{0, c}$ and $m_{f, c}$ are electrode masses of cathode before and after the discharge test, $Q$ is the total charge transferred $\left(Q=\int I t_{s}, \mathrm{C}\right)$, and $M$ is the molecular weight of copper $\left(63.55 \mathrm{~g} \mathrm{~mol}^{-1}\right)$. Similarly, the anodic coulombic efficiency $(A C E)$ was calculated as:

$$
\operatorname{ACE}(\%)=\frac{\frac{Q M}{2 F}}{\left(m_{o, a}-m_{f, a}\right)} \times 100
$$


where $m_{0, a}$ and $m_{f, a}$ are electrode masses of anode before and after the discharge test, measured using an analytical balance with a precision of $0.0001 \mathrm{~g}$.

\section{Results and discussion}

\subsection{Electrical power production}

A maximum power density of $85 \pm 3 \mathrm{~W} \mathrm{~m}^{-2}$ was produced by the TRENB with $2 \mathrm{M}$ ethylenediamine, which was higher than that of TRAB $\left(71 \pm 5 \mathrm{~W} \mathrm{~m}^{-2}\right)$ at the same added ligand (ammonia) concentration. The power density was further improved to $119 \pm 4 \mathrm{~W} \mathrm{~m}^{-2}$ by increasing the ethylenediamine concentration to $3 \mathrm{M}$ (Fig. 1a). Since the same electrolytes were used as the catholyte for both TRENB and TRAB, both batteries showed the same cathode potentials. A lower anode potential was observed for TRENB $(-0.164 \mathrm{~V}$ in average for different ethylenediamine concentrations) than that of TRAB $(-0.095 \mathrm{~V}$ in average), using a ligand concentration of $2 \mathrm{M}$. The anode potential of TRENB improved by using higher ethylenediamine concentrations, with $-0.202 \mathrm{~V}$ for $3 \mathrm{M}$ and $-0.221 \mathrm{~V}$ for $4.5 \mathrm{M}$ (Fig. 1b). The higher open circuit potential of TRENB (Fig. S4) relative to TRAB was due to the lower standard reduction potential of copper complexed with ethylenediamine of $-0.12 \mathrm{~V}$ (Eqn. 3) compared to that of copper complexed with ammonia (-0.04, Eqn. 2) [24]. The improved anode potential with the higher ethylenediamine concentration was consistent with potentials predicted by the Nernst equation (Eqn. S1). 

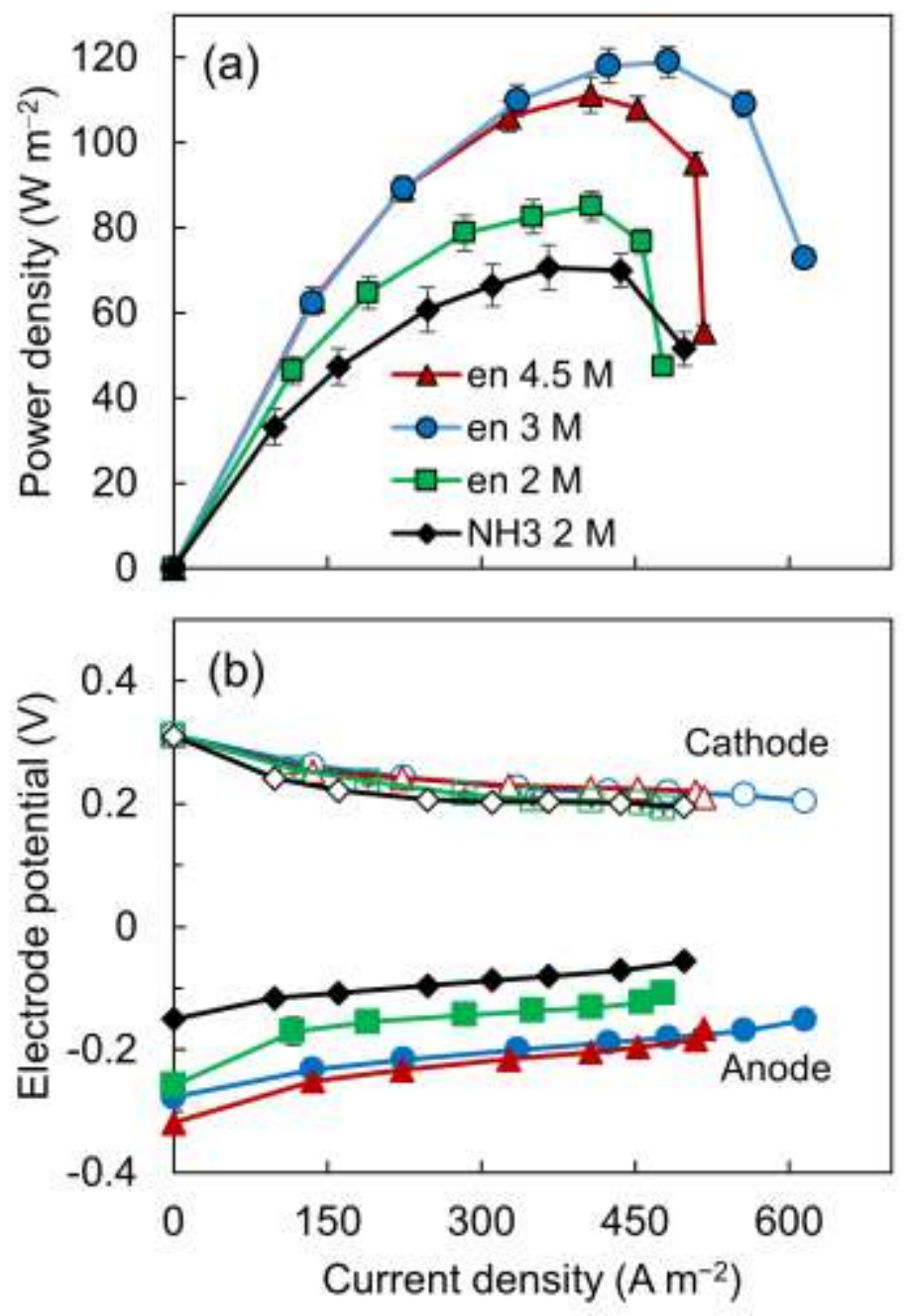

Fig. 1. (a) Power densities and (b) electrode potentials of TRAB (black) with ammonia, and TRENBs (colored) with different concentrations of ethylenediamine (en).

\subsection{Analysis of the cell resistances}

Based on EIS tests using a $2 \mathrm{M}$ ligand, the TRENB showed a higher ohmic resistance (i.e. sum of membrane and solution resistances; $2.12 \Omega$ ) than that of TRAB (1.74 $\Omega$ ) primarily due to its lower solution conductivity (245 mS/cm for TRENB and $368 \mathrm{mS} / \mathrm{cm}$ for TRAB). However, this increase in ohmic resistance was offset by a decrease in the reaction resistance from $1.66 \Omega$ (TRAB) to $0.92 \Omega$ (TRENB), making the overall resistance of TRENB lower than that of TRAB with the same concentration of ligand (Fig. 2). The ohmic resistance of TRENB was further 
enhanced by increasing the ligand concentration to $3 \mathrm{M}(2.55 \Omega)$ or $4.5 \mathrm{M}(3.06 \Omega)$ (Fig. 2). Increasing the ethylenediamine concentration enhanced the anolyte $\mathrm{pH}$ from 9.29 for $2 \mathrm{M}$ to 9.74 for $4.5 \mathrm{M}$, leading to the formation of neutrally charged ammonia from the positively charged ammonium, which exists as the supporting electrolyte (Eqn. S2; Fig. S5). This transfer from the charged species to the uncharged species decreased the solution conductivity, resulting in a higher solution resistance for a higher concentration of ethylenediamine.

The reaction resistance, which is the sum of anode and cathode charge transfer resistances, and the diffusion resistances, were lower with the TRENB (1.05 $\Omega$ in average) than that of TRAB (1.66 $\Omega$; Fig. 2). Changing the ligand from ammonia to ethylenediamine facilitated the electrochemical reactions or/and copper ions diffusion coefficient. This improvement resulted in the higher power production of TRENBs compared to that of the TRAB.

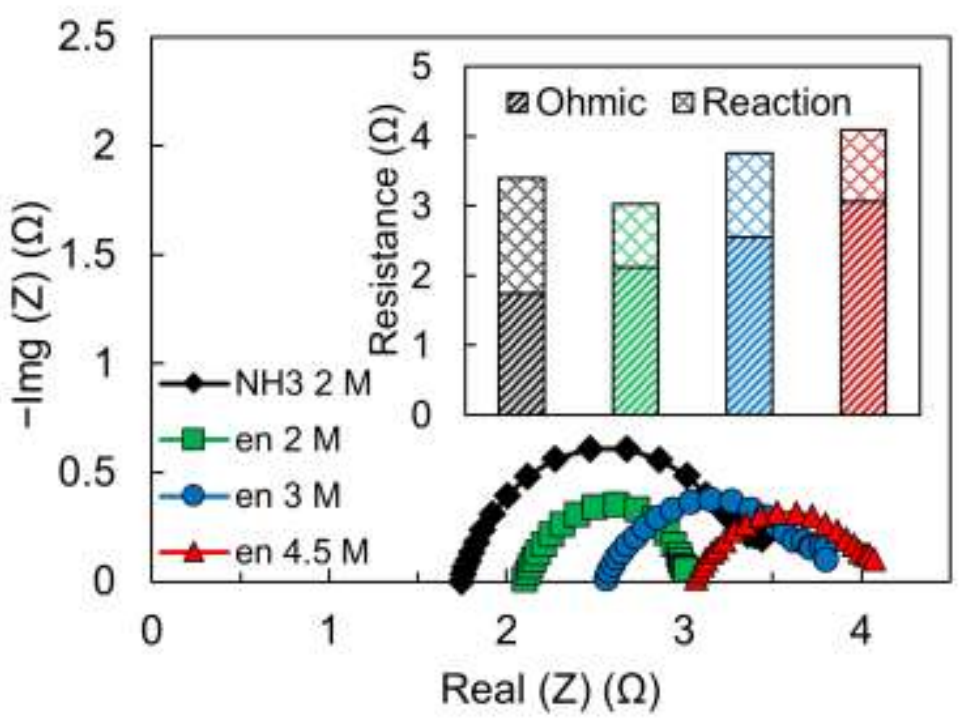

Fig. 2. Nyquist plots of the whole cell impedance at $0.2 \mathrm{~V}$ for TRAB with ammonia (black) and TRENBs (colored) with various concentration of ethylenediamine (en), all with a $0.1 \mathrm{M} \mathrm{Cu}$ (II) and $5 \mathrm{M} \mathrm{NH}_{4} \mathrm{NO}_{3}$ supporting electrolyte. The inserted Fig. indicates the components of impedance (ohmic and reaction) obtained by fitting the Nyquist plots to the equivalent simplified Randles circuit (Fig. S2).

\subsection{Discharge performance}


To evaluate energy production, power generation was examined over a complete discharge cycle (defined as a final cell voltage $<10 \mathrm{mV}$ ) at the external resistance which produced the maximum power in polarization tests. The energy densities of the TRENB were consistent with polarization tests, with $461 \mathrm{Wh} \mathrm{m}^{-3}$ produced at an ethylenediamine concentration of $2 \mathrm{M}$, and $478 \mathrm{Wh} \mathrm{m}^{-3}$ at $3 \mathrm{M}$. However, a further increase of ethylenediamine concentration to $4.5 \mathrm{M}$ (480 $\mathrm{Wh} \mathrm{m}^{-3}$ ) did not appreciably improve the energy density (Fig. 3). The electrical energy produced by the TRENB was $\sim 1.5$ times that obtained by the TRAB $\left(323 \mathrm{Wh} \mathrm{m}^{-3}\right)$ both with the same ligand concentration of $2 \mathrm{M}$. The total charge transfer of TRENB also followed the same trend as energy production, with 509 coulombs (C) for $2 \mathrm{M}, 532 \mathrm{C}$ for $3 \mathrm{M}$, and $565 \mathrm{C}$ for $4.5 \mathrm{M}$. Similar to the power and energy production, the total charge transfer of TRENBs were also higher than that of TRAB (420 C; Fig. 3b). By switching the ligand from ammonia to ethylenediamine, the discharge efficiency was slightly improved. For example, TRENB with the same ligand concentration as TRAB $(2 \mathrm{M})$ obtained a discharge efficiency of $\eta_{\mathrm{d}}=30 \%$. The discharging energy efficiency of the TRAB was $26 \%$, similar to that previously reported $[17,18]$ (Fig. 3b). 

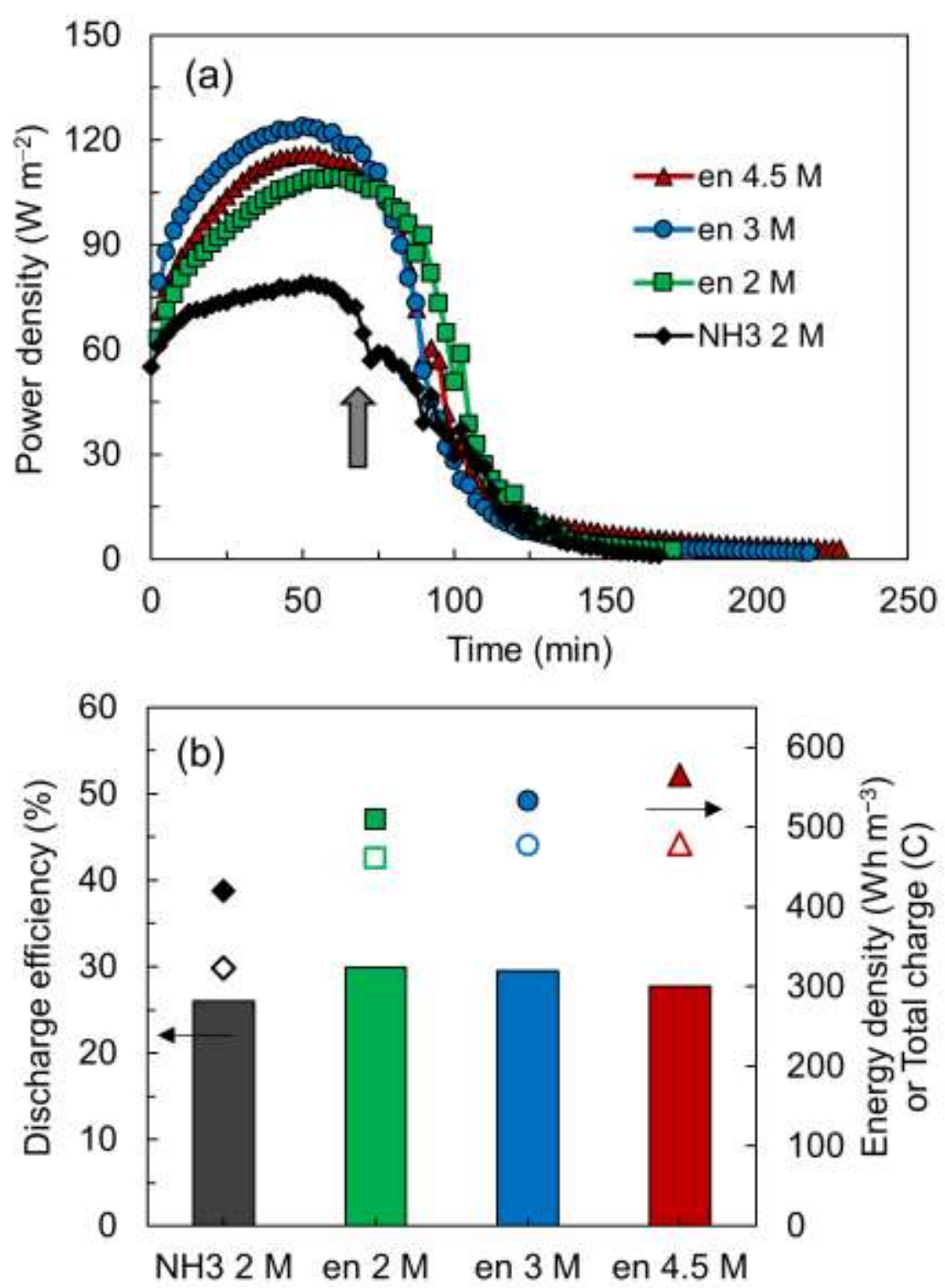

Fig. 3. (a) The discharge performance, (b) total charge (filled symbols), electrical energy density (open symbols) and discharge efficiencies (column) of TRAB with ammonia and TRENBs with various concentration of ethylenediamine (en). The initial electrolyte contained $0.1 \mathrm{M} \mathrm{Cu}$ (II) and $5 \mathrm{M} \mathrm{NH}_{4} \mathrm{NO}_{3}$ as the supporting electrolyte. The arrow in (a) shows when the anode electrode of TRAB was replaced; the anodes were not replaced for the TRENB.

Since a TRB would be operated in successive closed-loop cycles in which the electrodes alternatively function as cathode and anode, ideally the rate of corrosion of the anode must be the same as the rate of deposition on the cathode electrode. The corrosion and deposition rates of the 
electrodes were investigated by calculating the cathodic and the anodic coulombic efficiencies. The coulombic efficiency for the anode in a single TRENB cycle was ACE $=77 \pm 2 \%$, which was significantly higher than that of TRAB (35\%) (Fig. 4a). In both cases, a side reaction in which a species in the anolyte liked functioned as an alternative electron acceptor, resulting in an ACE $<100 \%$. The loss of the anode to a side reaction was reduced by replacing ammonia with ethylenediamine, thereby increasing the ACE. The cathodic coulombic efficiency was $\sim 100 \%$ for both TRENB and TRAB, which showed that all of the current in the cathode was consumed by the electrodeposition reaction of the copper ions $\left(\mathrm{Cu}^{2+} \rightarrow \mathrm{Cu}^{0}\right)$. As a result of the different anodic coulombic efficiencies, the difference between the cathode deposition and the anode corrosion rates for TRENBs (4 mg) was significantly lower than that of TRAB (60 mg; Fig. 4b). Unlike TRENB, the anode electrode of TRAB needed to be replaced by a new copper electrode during the discharge test due to a very high corrosion rate. 

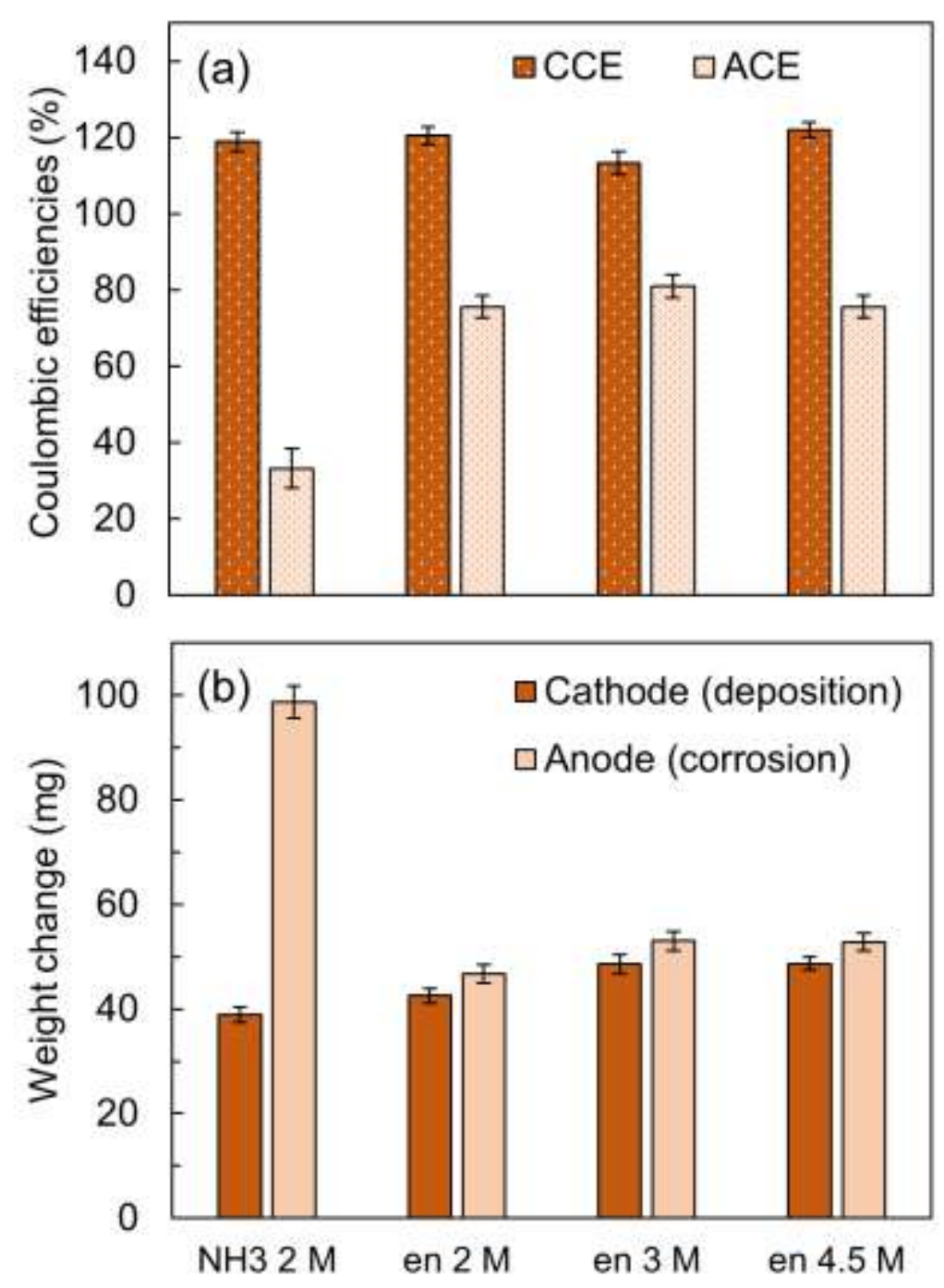

Fig. 4. (a) Cathodic (CCE) and anodic coulombic efficiencies (ACE), and (b) electrode weight change of cathodes and anodes of TRAB with ammonia and TRENBs with different concentration of ethylenediamine (en).

\subsection{Cyclic voltammetry study of TRBs}

To identify possible side reactions contributing to the low ACEs, the electrochemical behavior of the anode electrode was evaluated using cyclic voltammetry (CV) at different scan rates. For TRENB, a sharp decrease in the current at the vortex potential represented the copper deposition from $\mathrm{Cu}(\mathrm{II})$ complex to $\mathrm{Cu}(0)$, according to the reaction:

$$
\mathrm{Cu}(\mathrm{en})_{2}{ }^{2+}+2 \mathrm{e}^{-}=\mathrm{Cu}(0)+2 \mathrm{en}
$$


In addition, an anodic peak $\left(\mathrm{I}_{\mathrm{a}}\right)$ were observed which can be attributed to the anodic formation of $\left[\mathrm{Cu}(\mathrm{en})_{2}\right]^{2+}$ from $\mathrm{Cu}(0)$. The potential of this broad peak changed with the scan rate, suggesting that the kinetics of the electrochemical $\mathrm{Cu}(0)$ oxidation step were slow (Fig. 5a).

For TRAB, a different electrochemical behavior was observed. The cathodic peak $\left(\mathrm{II}_{\mathrm{c}}\right)$ at $-0.29 \mathrm{~V}$ was not followed by a sharp decrease in the current at the vortex potential, suggesting that no copper electrodeposition occurred (Fig. 5b). Peak $\mathrm{II}_{\mathrm{c}}$ can be attributed to the reduction of $\left[\mathrm{Cu}\left(\mathrm{NH}_{3}\right)_{4}\right]^{2+}$ to $\left[\mathrm{Cu}\left(\mathrm{NH}_{3}\right)_{2}\right]^{+}[25,26]$, according to:

$$
\mathrm{Cu}\left(\mathrm{NH}_{3}\right)_{4}{ }^{2+}+\mathrm{e}^{-}=\mathrm{Cu}\left(\mathrm{NH}_{3}\right)_{2}{ }^{+}+2 \mathrm{NH}_{3}
$$

Upon sweep reversal, a corresponding anodic peak $\left(\mathrm{II}_{\mathrm{a}}\right.$; copper complex oxidation) was also observed. Since for TRAB a symmetrical CV curve was achieved, it can be concluded that only a quasi-reversible reaction involving the copper complex occurred, without evidence for a deposition or dissolution electrochemical reaction. 

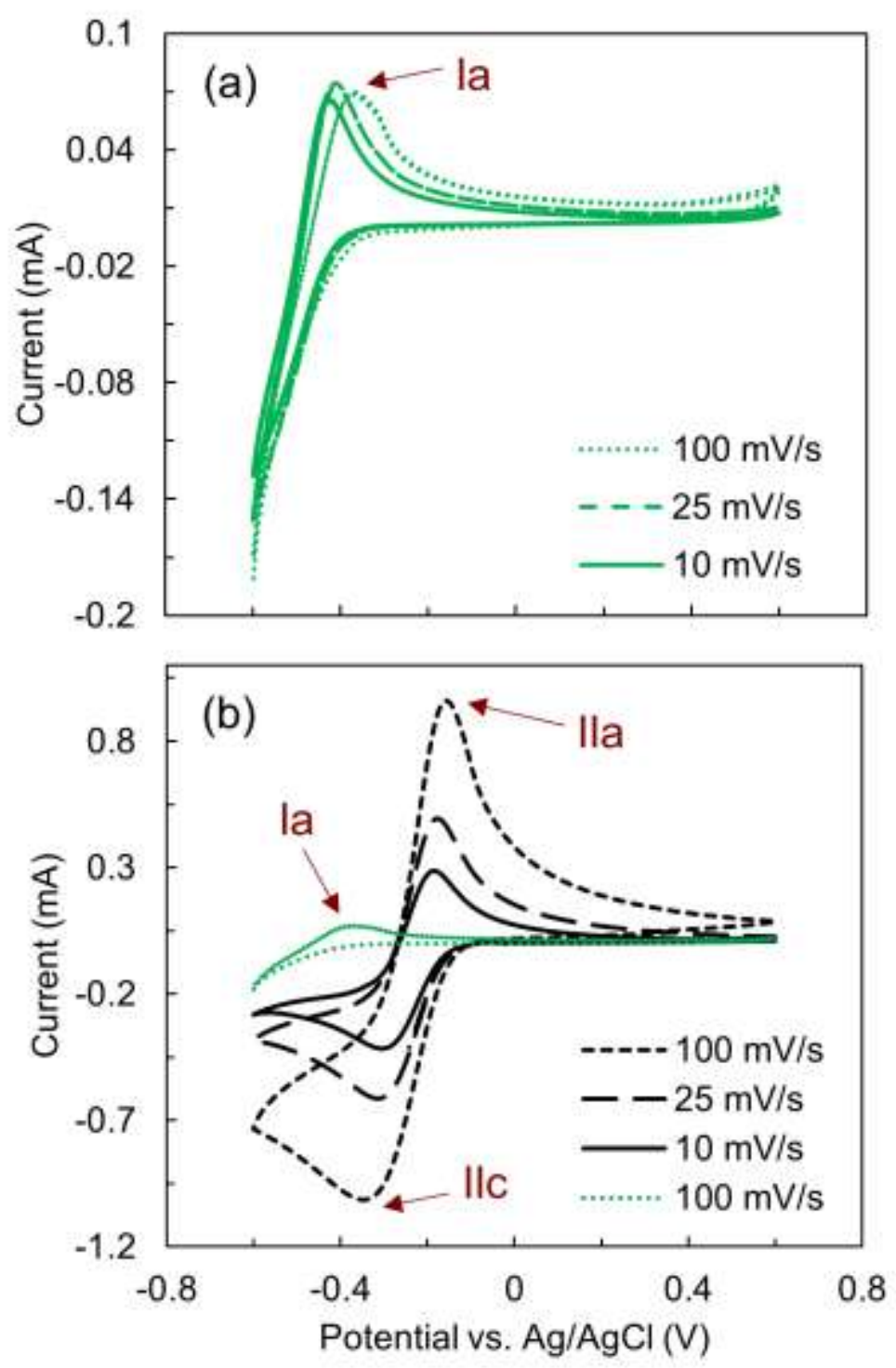

Fig. 5. Cyclic voltammograms of (a) TRENB, and (b) TRAB in the potential range of $-0.6 \mathrm{~V}$ to $0.6 \mathrm{~V}$ at different scan rates. An electrolyte with $0.1 \mathrm{M} \mathrm{Cu}\left(\mathrm{NO}_{3}\right)_{2}, 5 \mathrm{M} \mathrm{NH}_{4} \mathrm{NO}_{3}$ and $2 \mathrm{M}$ ligand was used. In part (b), the green line (TRENB) was used to better compare the peak currents of TRENB and TRAB.

The CVs help to explain the different coulombic efficiencies for the anodes with ethylenediamine or ammonia. In both cases, the positively charged complex was an electron acceptor, resulting in an ACE $<100 \%$. However, significantly lower peak currents were obtained for TRENB compared to that of TRAB (Fig. 5b). Therefore, the reduction of $\mathrm{Cu}(\mathrm{II})$-complex in 
TRENB is slower and/or less favorable than that in TRAB, which would explain a higher ACE of TRENB $(77 \pm 2 \%)$ than that of TRAB $(35 \%)$.

\subsection{Recharging the electrolytes}

In order to charge a TRB, the ligand needs to be separated off from the anolyte and re-dissolved in the catholyte. The ethylenediamine-water mixture has an azeotrope with a maximum separation point of 0.55 (molar fraction), so the fractional distillation proposed for TRAB could not be used for a TRENB [27-29]. Therefore, other separation methods, such as an azeotropic distillation or pressure swing distillation would need to be used to separate ethylenediamine and water using waste heat. In order to calculate an energy efficiency for converting waste heat into electricity, we examined the use of an azeotropic distillation using acetone as the solvent. The results showed that ethylenediamine, with a purity of $92 \%$, could be separated using a threecolumn separation unit (Fig. S6). For TRAB recharge, the energy for separation was evaluated for a distillation column with a reboiler temperature of $70.4{ }^{\circ} \mathrm{C}$, a condenser temperature of 43.3 ${ }^{\circ} \mathrm{C}$, and low-grade waste heat $\left(<130^{\circ} \mathrm{C}\right)$ as the energy source was used $[17,18,30]$. The energy requirement to recharge the TRENB was calculated as $615 \mathrm{~kW} \mathrm{~h} \mathrm{~m}^{-3}$-anolyte, which was $\sim 2.5$ times more than that required by the $\operatorname{TRAB}\left(245 \mathrm{~kW} \mathrm{~h} \mathrm{~m}^{-3}\right)$. Based on this estimation, the thermal-electric conversion efficiency of the TRENB was $0.52 \%$, which was lower than that of the TRAB $(0.86 \%)$ despite its higher power and energy production. This suggests that a greater optimization of regeneration process of ethylenediamine for the TRENB process could greatly improve overall energy efficiency. Alternative separation approaches or conditions should therefore be examined to improve the overall thermal efficiency of the process. 


\section{Conclusions}

A thermally regenerative battery based on using an ethylenediamine ligand was investigated to harvest low-grade waste heat as high electrical power. Compared to the previously developed battery based on using an ammonia ligand, the ethylenediamine system had a 1.7 times higher power density and 1.5 times higher energy production than that obtained using ammonia. In addition, the coulombic efficiency of the anode $(\sim 80 \%)$ was significantly higher than that of TRAB (35\%), resulting in less difference between copper corrosion and deposition rates on the electrodes. The overall energy efficiency of the TRENB of $0.52 \%$ could easily be improved by optimization of the ethylenediamine separation process, which would lead to a more efficient process for converting low-grade waste heat into electrical power.

\section{Acknowledgments}

The authors would like to thank Zach Schoener for his assistance to run some initial experiments.

The research was supported by award CBET-1464891 from the National Science Foundation.

\section{References}

[1] S. Chu, A. Majumdar, Nature 488 (2012) 294-303.

[2] C. Forman, I.K. Muritala, R. Pardemann, B. Meyer, Renew. Sust. Energ. Rev. 57 (2016) 1568-1579.

[3] F.X. Meng, H.G. Zhang, F.B. Yang, X.C. Hou, B. Lei, L. Zhang, Y.T. Wu, J.F. Wang, Z.C. Shi, Appl. Therm. Eng. 110 (2017) 779-786.

[4] T. Kim, M. Rahimi, B.E. Logan, C.A. Gorski, ChemSusChem 9 (2016) 981-988.

[5] A.P. Straub, N.Y. Yip, S. Lin, J. Lee, M. Elimelech, Nat. Energy 1 (2016) 16090.

[6] A. Carati, M. Marino, D. Brogioli, Energy 93, Part 1 (2015) 984-993.

[7] H.R. Dastgerdi, P.B. Whittaker, H.T. Chua, Desalination 395 (2016) 57-71.

[8] E.M. Dede, P. Schmalenberg, C.M. Wang, F. Zhou, T. Nomura, AIP Adv. 6 (2016) 6.

[9] T.J. Abraham, D.R. MacFarlane, J.M. Pringle, Energy Environ. Sci. 6 (2013) 2639-2645.

[10] X. Zhu, T. Kim, M. Rahimi, C. Gorski, B. Logan, ChemSusChem 10 (2017) 797-803.

[11] R. Koerver, D.R. MacFarlane, J.M. Pringle, Electrochim. Acta 184 (2015) 186-192.

[12] T. Liao, L. Cai, Y. Zhao, J. Chen, J. Power Sources 306 (2016) 666-673.

[13] E.H.B. Anari, M. Romano, W.X. Teh, J.J. Black, E. Jiang, J. Chen, T.Q. To, J. Panchompoo, L. Aldous, Chem. Commun. 52 (2016) 745-748.

[14] R. Hu, B.A. Cola, N. Haram, J.N. Barisci, S. Lee, S. Stoughton, G. Wallace, C. Too, M. Thomas, A. Gestos, M.E.d. Cruz, J.P. Ferraris, A.A. Zakhidov, R.H. Baughman, Nano Lett. 10 (2010) 838-846. 
[15] H. Im, T. Kim, H. Song, J. Choi, J.S. Park, R. Ovalle-Robles, H.D. Yang, K.D. Kihm, R.H. Baughman, H.H. Lee, T.J. Kang, Y.H. Kim, Nat. Commun. 7 (2016).

[16] T.I. Quickenden, Y. Mua, J. Electrochem. Soc. 142 (1995) 3985-3994.

[17] F. Zhang, J. Liu, W. Yang, B.E. Logan, Energy Environ. Sci. 8 (2015) 343-349.

[18] X. Zhu, M. Rahimi, C.A. Gorski, B. Logan, ChemSusChem 9 (2016) 873-879.

[19] M. Rahimi, Z. Schoener, X. Zhu, F. Zhang, C.A. Gorski, B.E. Logan, J. Hazard. Mater. 322 (2017) 551556.

[20] A.J. Bard, R. Parsons, J. Jordan, Standard potentials in aqueous solution, Taylor \& Francis, 1985.

[21] S.G. Bratsch, J. Phys. Chem. Ref. Data 18 (1989) 1-21.

[22] M. Rahimi, L. Zhu, K.L. Kowalski, X. Zhu, C.A. Gorski, M.A. Hickner, B.E. Logan, J. Power Sources 342 (2017) 956-963.

[23] T. Kim, M. Rahimi, B.E. Logan, C.A. Gorski, Environ. Sci. Technol. 50 (2016) 9791-9797.

[24] K. Srinivasan, R.S. Subrahmanya, J. Electroanal. Chem. Interfacial Electrochem. 31 (1971) 257-263.

[25] D. Grujicic, B. Pesic, Electrochim. Acta 50 (2005) 4426-4443.

[26] A. Ramos, M. Miranda-Hernández, I. González, J. Electrochem. Soc. 148 (2001) C315-C321.

[27] Å.U. Burman, K.H.U. Ström, J. Chem. Eng. Data 58 (2013) 257-263.

[28] A. Valtz, C. Coquelet, C. Nikitine, D. Richon, Thermochim. Acta 443 (2006) 251-255.

[29] B. Sheikh, A. Pak, Phys. Rev. E 91 (2015) 053301.

[30] F. Zhang, N. LaBarge, W. Yang, J. Liu, B.E. Logan, ChemSusChem 8 (2015) 1043-1048. 


\section{Graphical Abstract}

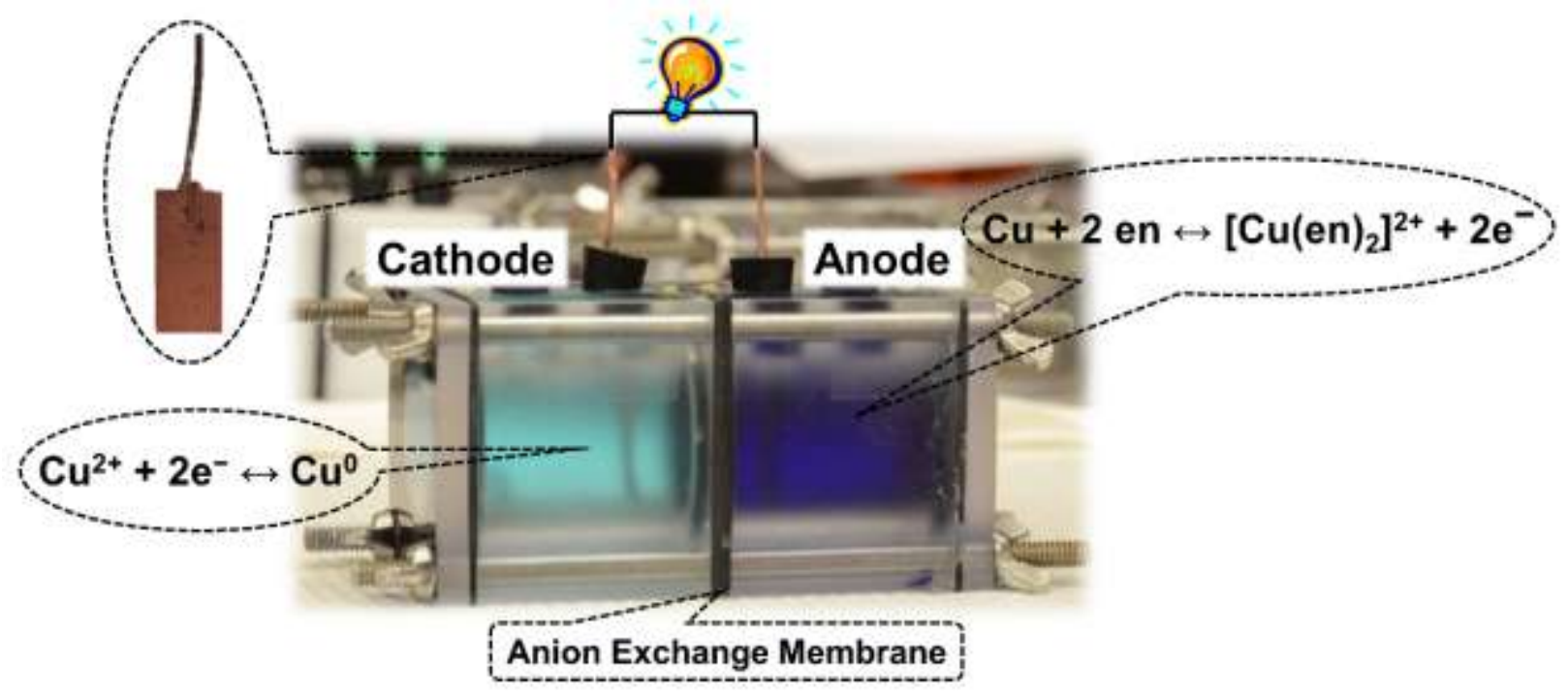

